\title{
Function and performance targets in ecological rehabilitation
}

\author{
RJ Loch Landloch Pty Ltd, Australia
}

\begin{abstract}
This paper considers, from the view of a rehabilitation practitioner, approaches to establishing a sustainable ecosystem that may reasonably approximate some target vegetation assemblage. Broadly, the target system needs to be defined not only in terms of species assemblages, but also in terms of key soil attributes; some of which may be relatively constant and able to be established when revegetation works are carried out. However, other soil attributes may rely on plant growth for their development and modification, and the role of vegetation in providing essential services to the developing ecosystem is fundamental to long-term ecosystem sustainability. This paper demonstrates how runoff/erosion and water balance models could be used to provide quantitative short- and longer-term targets for the management and assessment of rehabilitation progress and success.
\end{abstract}

\section{Introduction}

Mine site rehabilitation activities in Australia occur across a wide range of climatic zones, and attempt to meet rehabilitation goals that can vary widely from site to site. Because the goals that are set largely determine both the rehabilitation strategy(ies) applied and the eventual assessment of success or failure, the methods by which goals are set are a critical consideration for rehabilitation practitioners.

Approaches to ecosystem establishment are still strongly influenced by the concepts of Clements (1916), who envisaged well-defined stages of succession through to a relatively constant climax vegetation, with each stage creating changes in soil and microclimate that facilitate development of the next stage. Although less simplistic views are now more widely adopted (e.g. Whittaker 1953), some aspects of the succession concepts are quite relevant to mine site revegetation. There are pioneer plants that are adapted to colonise disturbed areas. Changes in soil properties do occur as a result of plant growth, and such changes may be critical to the development and resilience of an ecosystem, and to gradual changes in species composition and ecosystem form.

Nonetheless, the concept of a fixed and predictable climax vegetation is not helpful. There is extensive evidence that broad land areas naturally support a range of edaphic climax communities, where ecosystem development is controlled or limited by soil and landscape conditions (soil water, nutrients, topography, aspect). For example, with respect to the distribution of Brigalow (Acacia harpophylla) in Queensland and northern New South Wales, it is reported by Isbell (1962) that:

"Brigalow vegetation is usually associated with deep gilgaied clays, sedentary clays, alluvial clays, miscellaneous deep clays and loamy red soils."

Similarly, NSW Department of Environment, Climate Change and Water (DECCW) (2010) notes, with respect to Brigalow, that:

"The closed canopy form of the community consists of stands of Acacia harpophylla found on deep gilgaied clay soils on gently undulating country, forming dense forests to $25 \mathrm{~m}$ high. Brigalow also forms a low woodland with moderately dense canopy, dominated by small trees of $A$. harpophylla with pockets of vegetation dominated by belah, poplar box or Pilliga box. This variation relates to site drainage characteristics, with belah favouring sites of impeded drainage, and Pilliga box areas with better drainage." 
Observations of variation in vegetation in response to soil and landscape variation are common in soil survey reports throughout Australia.

It is likely that most mine site revegetation could be classed as edaphically controlled. Similarly, there are potential impacts of (or disturbances by) weeds, fire, drought, feral animals and humans that make the eventual development of a fixed and predictable vegetation assemblage implausible, with concepts of a range of natural ecological variability in time and space (Landres et al. 1999) being more appropriate.

As a consequence, setting rehabilitation goals on the basis of defined species (or on ranges thereof) could be considered to be doomed to failure. Without addressing all of the ecosystem attributes that support the target vegetation assemblage, a focus on species and species diversity alone is effectively trying to fit a square vegetative peg into an ill-defined environmental hole that may (in fact) be round.

Adding to the challenge is that some of the key environmental attributes for the target ecosystem may not be able to be created by revegetation contractors during initial works; with sites relying instead on impacts of initial vegetative growth to modify soil and environment and create the necessary conditions.

If effective and acceptable mine site rehabilitation is to be more reliably achieved, two changes in approach appear essential. The first is that the definition of 'ecosystem' should routinely include considerations of soil function in terms of physical, chemical, and biological properties. The second is that success criteria need to be expanded to include the progressive development of a range of 'ecosystem services' that are essential for ecosystem development and resilience.

This paper focuses on some soil properties and some of the essential ecosystem services. A more thorough treatment is beyond the scope of a conference paper.

\section{Important ecosystem services}

For plant communities to be sustainable, the plants require a range of inputs that (in this paper) are considered as 'services'. These often include:

- Interception of rainfall and reduction of runoff.

- Storage and availability of water in soil.

- Supply of essential plant nutrients (from mineral, organic, and microbial pools).

- Landscape stability (thereby limiting erosion, loss of nutrients, and soil degradation).

These services can vary greatly in both type and importance from soil to soil, but - for a given soil, can also develop through time, often as a result of interactions between vegetation and soil.

\subsection{Soil}

Soil properties have enormous impact on vegetation establishment, and on ecosystem development and resilience. Importantly, some properties could be considered 'constant', undergoing little or slow change through time unless there is direct intervention or amelioration. Others will vary through time to a significant degree and some will vary greatly in response to plant growth. Other properties, such as soil water content, can change on a daily basis and are not considered in this discussion.

For the purposes of this paper, which deals with site rehabilitation and ecosystem development through time, this paper will focus on temporal changes. Spatial variation in soils and associated vegetation has been used solely to demonstrate the impacts of soil properties on ecosystems.

Relatively constant (constant through time) soil properties include texture, clay mineralogy, soil depth, Plant Available Water Capacity (PAWC) and totals of some essential plant nutrients such as phosphorus and potassium that are only very slowly accrued through time unless added as fertiliser. These relatively unchanging properties set limits on soil productivity and, if insufficient to support the target vegetation, will ensure unacceptable outcomes. 
Soil properties that can change to a significant degree over periods of several years could include soil organic carbon, soil aggregation and aggregate stability, various forms of essential nutrients such as $\mathrm{P}, \mathrm{N}$ and $\mathrm{S}$, together with soluble salt profiles and exchangeable cation concentrations.

This is illustrated by Figure 1, taken from Loch and Orange (1997). It shows changes in a number of surface soil properties with time since rehabilitation for a coal mine in southern Queensland. The dominant vegetation was grass. The \% aggregates $<0.125 \mathrm{~mm}$ is a measure of unstable (surface seal forming) particles, so its reduction is regarded as a positive change in soil structure, as are increases in hydraulic conductivity and organic carbon.

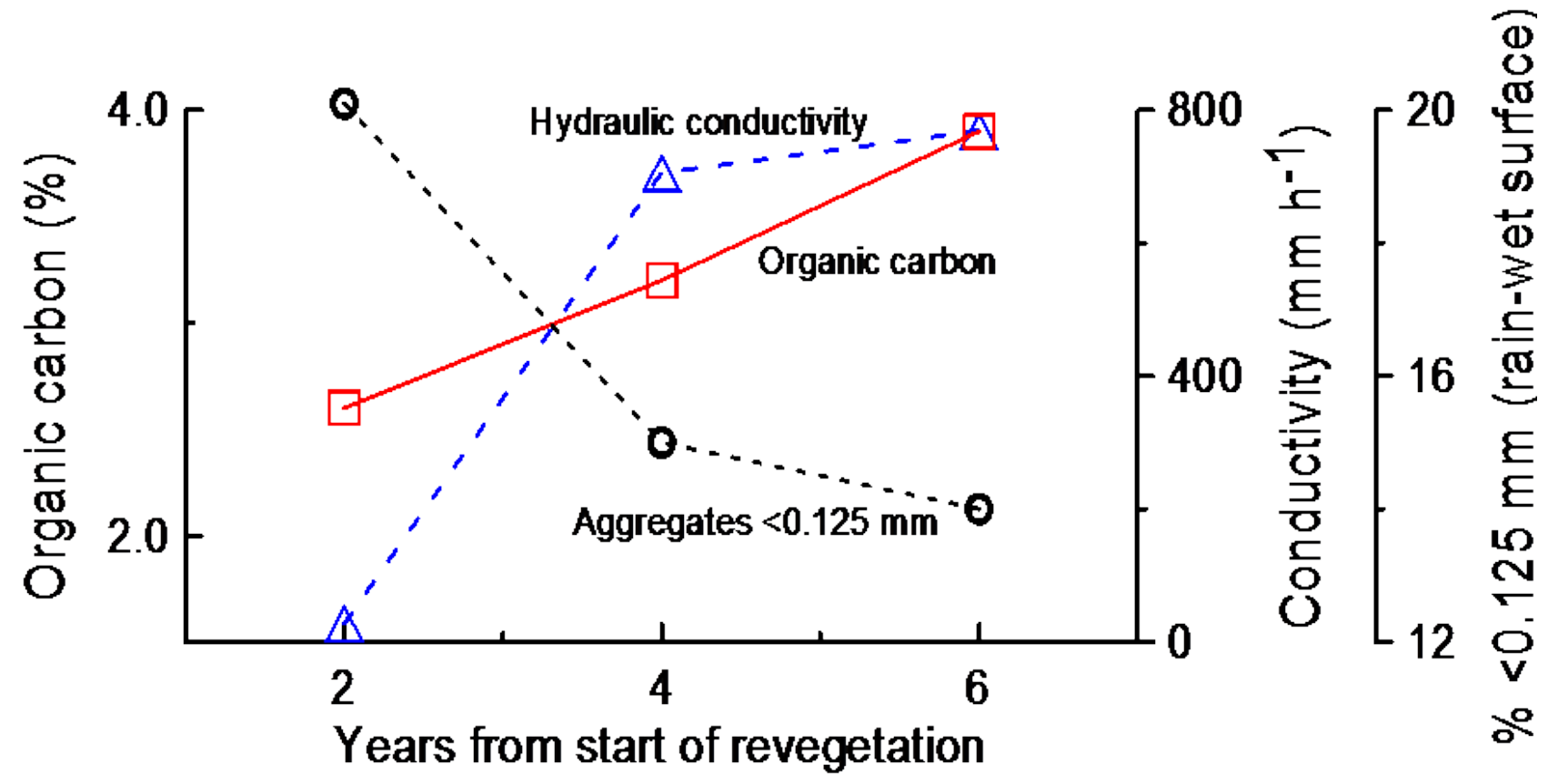

Figure 1 Changes through time from rehabilitation some surface soil properties, for a coal mine site in southern Queensland (from Loch and Orange 1997)

Changes in soil properties are likely to be greater in situations where plant growth is vigorous (higher rainfall and/or higher soil fertility for example), as addition of organic matter to the soil will therefore be greater. For some areas, there can be large changes in soil organic carbon accompanied by increases in soil aggregation and in infiltration capacity (Loch \& Orange 1997; Carroll et al. 2000; Carroll \& Tucker 2000; Schwenke et al. 2000; Loch 2000a, 2000b). The soil organic pool is an important source of nutrients, with annual vegetation growth being, in some cases, constrained by the rate of release of scarce elements often $P$ - from the organic pool (Westman 1978).

There are direct effects of vegetation on infiltration capacity (Loch 2000b) due to surface protection from raindrop impact (reducing surface seal development; Loch and Foley (1994)), and the presence of roots creating macropores that strongly increase infiltration rates (Figure 2). Kato et al. (2009) reviewed published experimental data from a range of studies, and found that the consolidated data set showed a consistent increase in steady infiltration rate of $7-10 \mathrm{~mm} / \mathrm{h}$ for each $10 \%$ increase in surface contact cover. Increases in hydraulic conductivity and infiltration rates can dramatically reduce potential annual runoff, as demonstrated in Figure 3 (Loch 2010). 


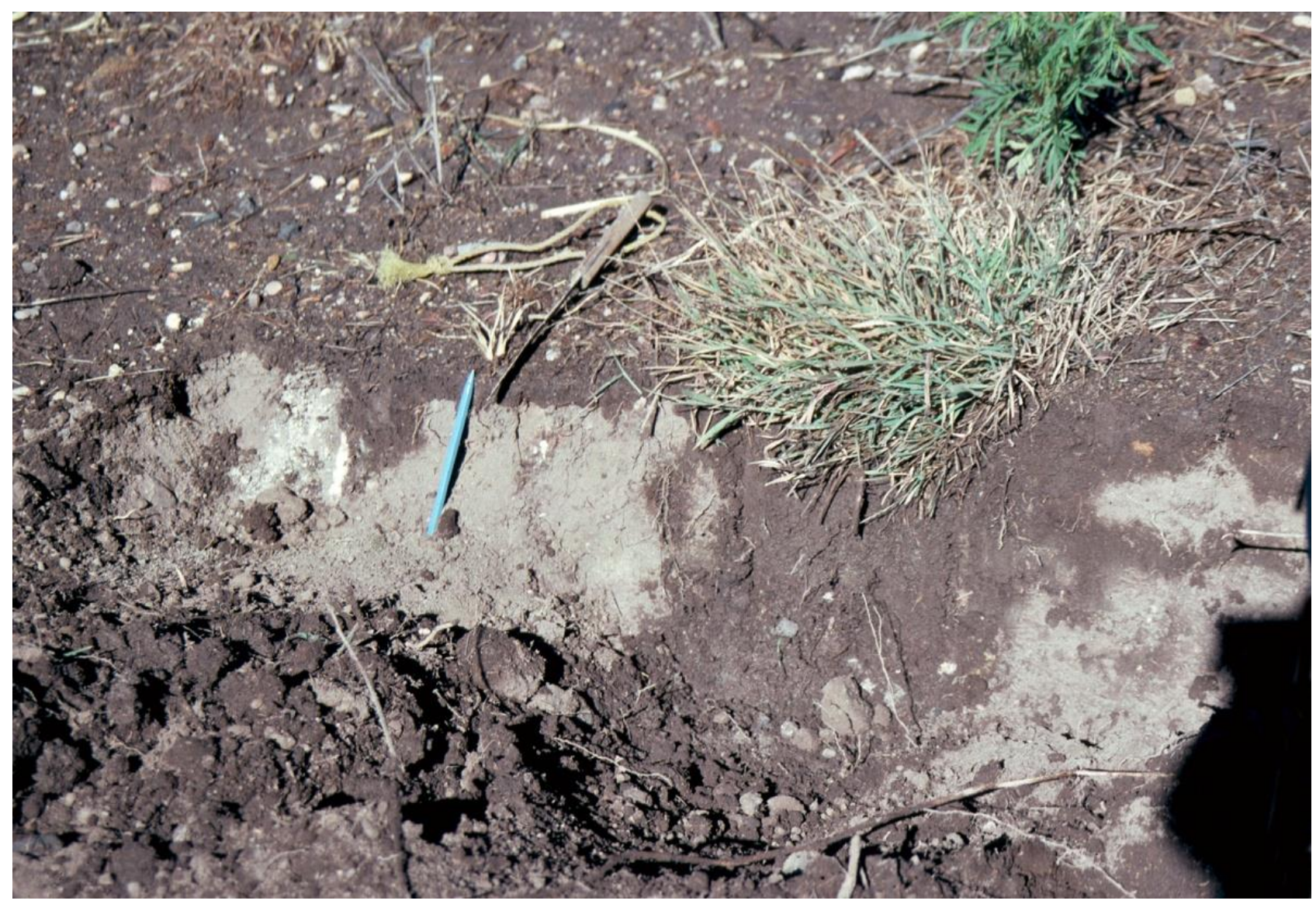

Figure 2 Shallow soil profile following application of simulated rain and runoff. Note increased depth of wetting (darker soil) under the grass tussock — associated with the plant root system

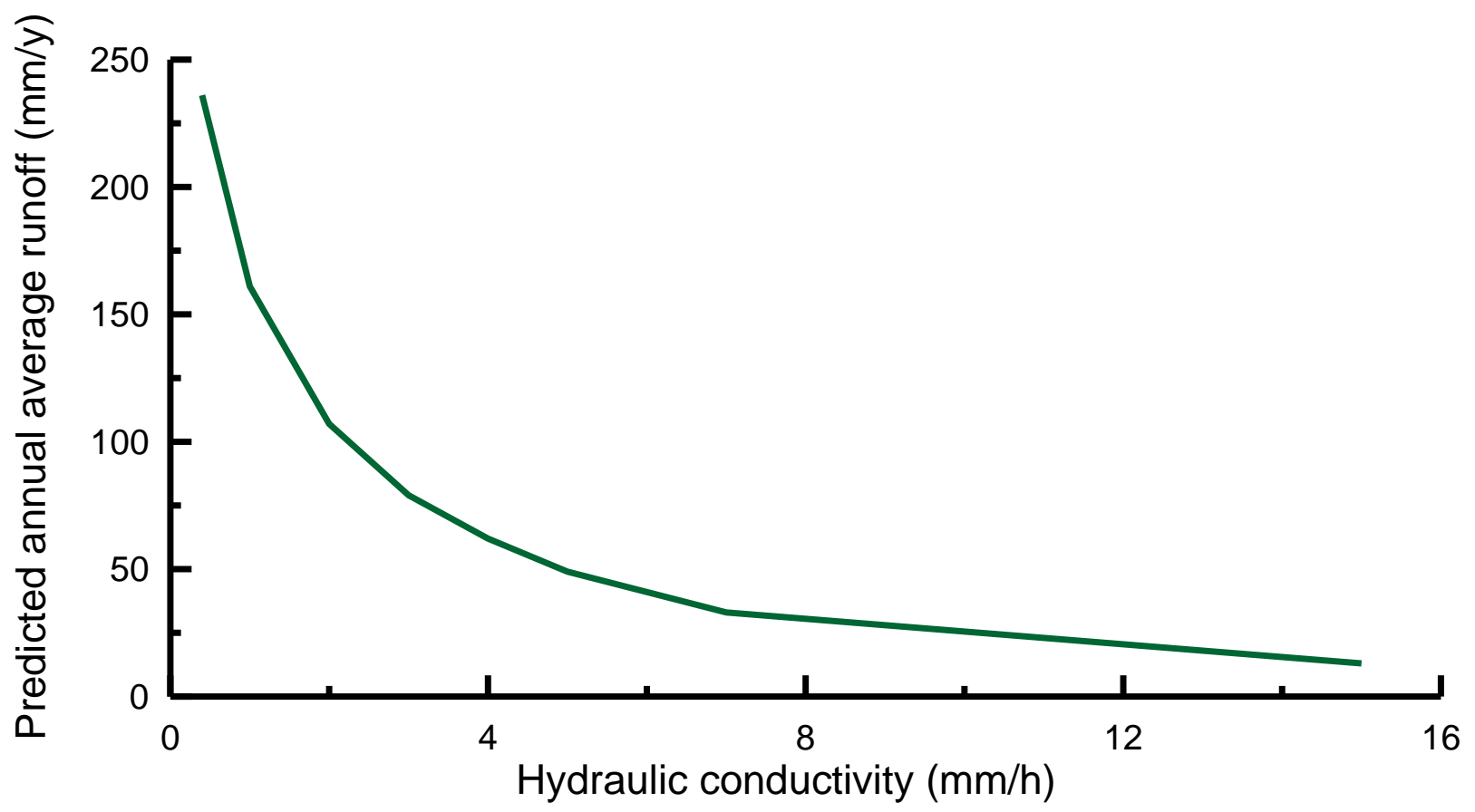

Figure 3 Predicted impact of soil hydraulic conductivity on annual average runoff - Hunter Valley topsoil and climate (soil hydraulic conductivity without gypsum amendment was $0.4 \mathrm{~mm} / \mathrm{h}$ ). Source: Loch (2010) 


\section{$2.2 \quad$ Vegetation}

Soil properties commonly interact strongly with vegetation. For example, where soil fertility and rainfall are sufficient, initial vegetation growth can:

- Increase surface cover, reducing runoff and erosion by water.

- In some environments, increase effective surface roughness and control erosion by wind.

- Increase soil organic matter, thereby improving soil structure, increasing infiltration and reducing soil erodibility.

- Develop an active organic pool within the soil that acts as a store of nutrients and that aids in the retention of applied (fertiliser) nutrients.

Acacias and other legumes can also gradually increase soil nitrogen (Koch 1987; Ward \& Pickersgill 1985; Ward et al. 1990; Ward 2000).

In more arid environments, cryptogam development may be essential to both stabilise the re-formed and rehabilitated surface and to re-establish the source-sink surface hydrology that is a critical feature of desert ecosystems (Eldridge et al. 2002).

\section{$3 \quad$ Setting targets}

In setting targets for rehabilitation, planning should consider:

- What are the key risks to ecosystem development and sustainability?

- What specific ecosystem services are essential to mitigate those risks?

More usefully, those considerations would be expanded to include the ways in which both risks and key attributes might vary through time.

\subsection{Relatively constant soil services}

For nutrients, total ecosystem quantities of various elements can be critical. But it should be noted that for elements in short supply - a significant proportion of some nutrients in a mature ecosystem may be held in the standing biomass, with an even greater proportion held in the organic pool and becoming slowly available for continued plant uptake and growth.

For elements such as $\mathrm{N}$ that can be accumulated by leguminous plants, a shortfall in the total $\mathrm{N}$ amount can be addressed by plant growth over time, but for elements such as $\mathrm{P}$ and $\mathrm{K}$ for which totals will change only very slowly under natural processes, application of fertiliser may be essential to address shortfalls.

However, for a developing ecosystem, it may be quite dysfunctional for the freshly-placed soil to hold the equivalent of an ecosystem's total required nutrient largely as soluble fertiliser, in a form that is highly-available to vegetation. Weed growth may be encouraged, some plants may have a serious competitive disadvantage, and a significant proportion of the nutrient may be lost (leached or immobilised). Over-fertilisation is likely to be as dysfunctional as under-fertilisation.

In some cases where relatively large amounts of fertiliser are to be applied, a short (1-3 year) period of predominantly grass growth may be useful to take up nutrients from fertiliser and rapidly transfer them into the organic pool, whilst also increasing organic matter levels.

In other cases, slow-release fertiliser can provide a slightly more gradual delivery of nutrients, and organic amendments are useful sources of slow-release nutrient in some situations.

Nonetheless, where relatively large quantities of nutrients such as $\mathrm{P}$ or $\mathrm{K}$ are required to reach ecosystem requirements, follow-up fertilisation may be unavoidable if ecosystem total nutrient stores are to be re-established without impacts of over-supply of those nutrients on developing ecosystems. 
Generally, failing to deliver ecosystem requirements with respect to total and available nutrient levels will result in poor growth, and potential for the area to be dominated by species of low vigour and low biomass production with higher tolerance of poor fertility. Increased erosion may then result from poor plant growth and reduced surface cover.

Where PAWC is low, a common consequence is that plant density is low. Effectively, the low PAWC profile is augmented by each plant accessing a wider area and, therefore, larger volume of soil to compensate for the reduced level of water storage in each unit depth of soil. In some instances, low PAWC may not change the assemblage of plants that establish, but the plant density, annual biomass production, surface cover, infiltration, and resistance to erosion (if on a sloping site) may all be reduced.

\subsection{Vegetation services and targets}

For a waste landform batter, erosion is often the major short-term risk. Consequently, erosion simulations might be used to consider what initial levels of surface cover are needed to control erosion during the period when soil cohesion is low and its erodibility is highest. Once it has been determined what level of cumulative erosion is acceptable, runoff/erosion modelling can be used to assess monthly erosion risk (example in Figure 4) and determine what levels of surface cover are needed at specific times within the first or second growing season to provide the necessary erosion control.

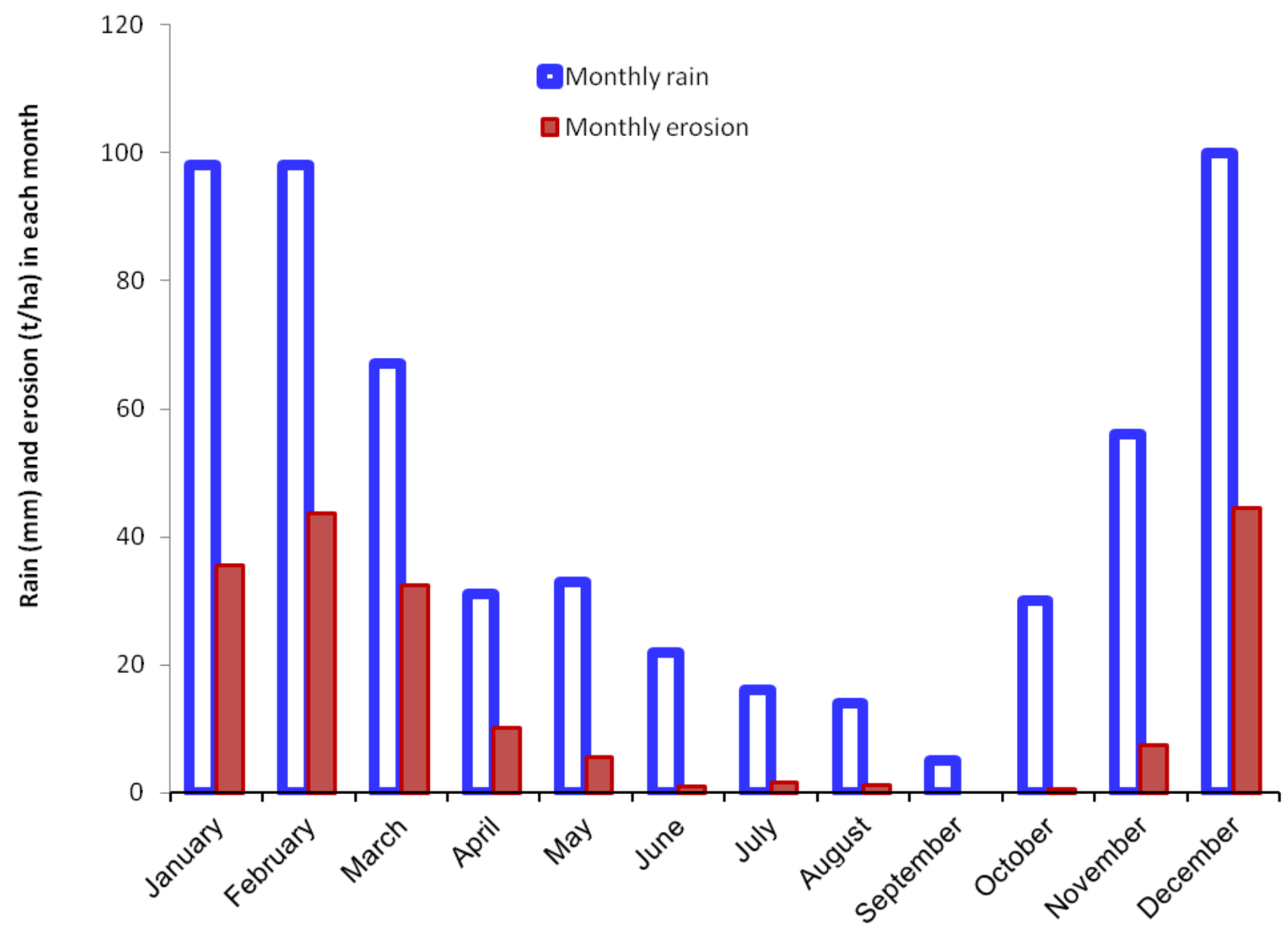

Figure 4 Monthly averages for rain and erosion (15\% gradient slope of bare soil, $80 \mathrm{~m}$ long), WEPP model simulations for a coal mine in central Queensland based on a 100-year climate file

Of course, such simulations may also determine that vegetation alone is unlikely to provide the necessary erosion control, and then other options such as the addition of tree debris or rock may also be required to achieve the necessary level of short-term cover and surface stability (Loch \& Lowe 2008; Howard et al. 2010; Squires et al. 2012). 
For longer-term considerations, improvement in soil structure and reduction in annual runoff may be essential. For sites with high erosion risk, species such as grass that can rapidly produce high levels of biomass, high root densities near the surface, and high levels of surface cover may be most effective in driving those changes, whereas trees and shrubs are much slower to have any impact on runoff and erosion (Carroll et al. 2000) and are better suited to sites for which vegetation impacts are less critical. Rainfall simulation studies and data on trends in infiltration capacity and soil erodibility (see e.g. Loch 2000a, $2000 \mathrm{~b}$ ) could be used to assess rates of soil development, and may - for example - identify needs for additional soil amendment if sodicity and clay dispersion mean that excessive runoff, erosion, and hardsetting are limitations to site stability and to ecosystem development.

For example, Figure 5 shows rainfall simulator data for the NorthParkes Mine (from Loch 2000a). It demonstrates impacts of both surface cover and length of time under vegetation on the runoff parameter Curve Number, which has been widely used in modelling daily runoff (Littleboy et al. 1996). The data show a quite significant decrease in curve number between 1-year old (upper b batter) and 2-year old (lower batter) revegetation. Decreasing curve number indicates increasing infiltration capacity. Other data for this site (Loch 2000a) show improvements in aggregate stability to wetting and a reduction in soil erodibility between 1 and 2 year's revegetation.

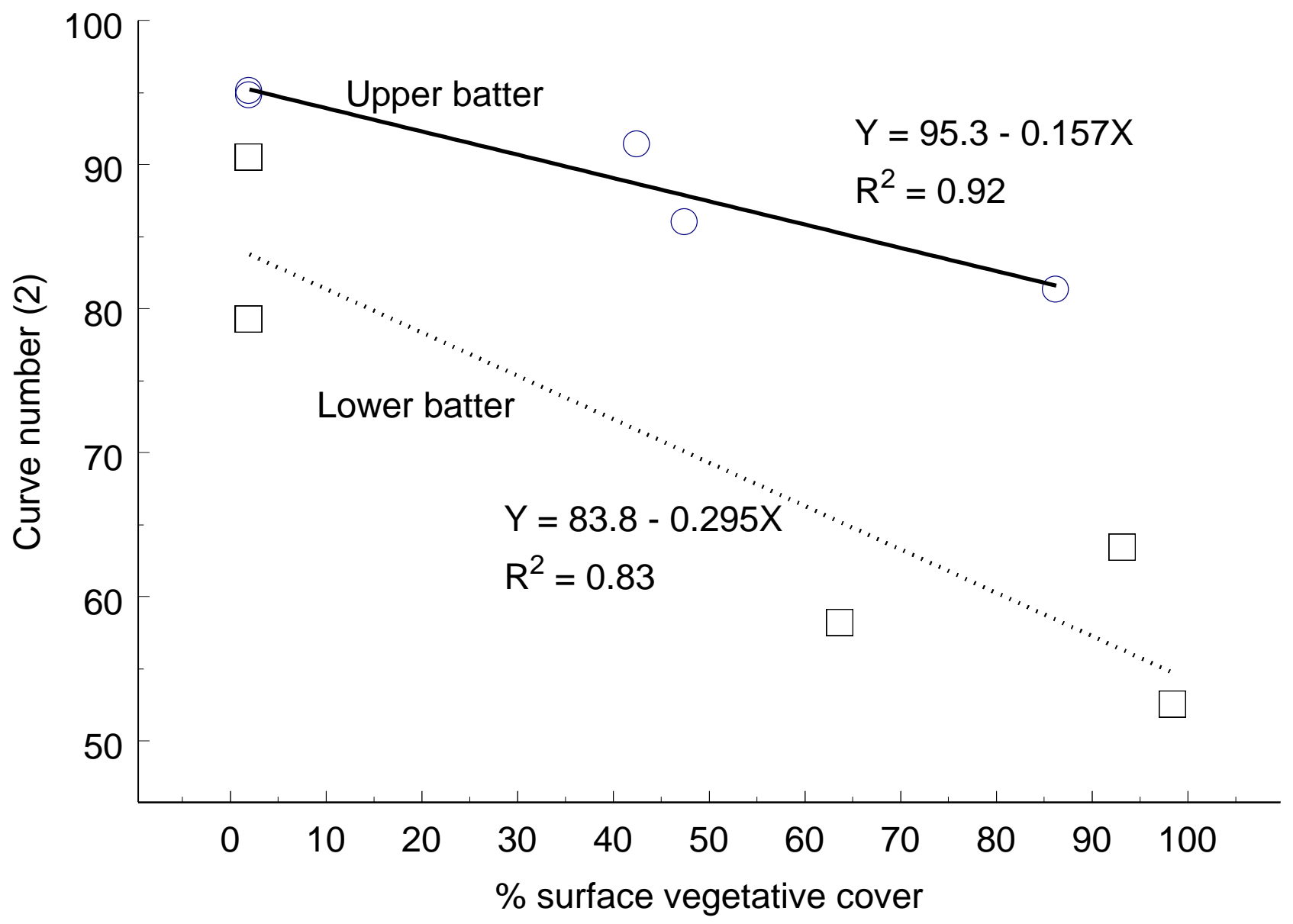

Figure 5 Effects of vegetation cover and length of time since rehabilitation on runoff curve number. Data from rainfall simulator study by Loch (2000a). (Upper batter had been rehabilitated for one year, the lower batter for two years.) The lower runoff curve number, the lower the amount of runoff estimated

Figure 6 shows the use of runoff/erosion modelling to assess the potential impacts of soil infiltration capacity (alone) on slope erosion potential, indicating that hydraulic conductivity of at least $6 \mathrm{~mm} / \mathrm{h}$ is highly desirable for soils used in rehabilitation in that area. As the soil in question was sodic and quite impermeable (hydraulic conductivity of $0.4 \mathrm{~mm} / \mathrm{h}$ ), the simulations clearly demonstrate the need for soil 
improvement (amendment with gypsum) to reduce the level of erosion risk to a level that can then (hopefully) be able to be controlled using vegetation cover - which could then increase soil hydraulic conductivity further.

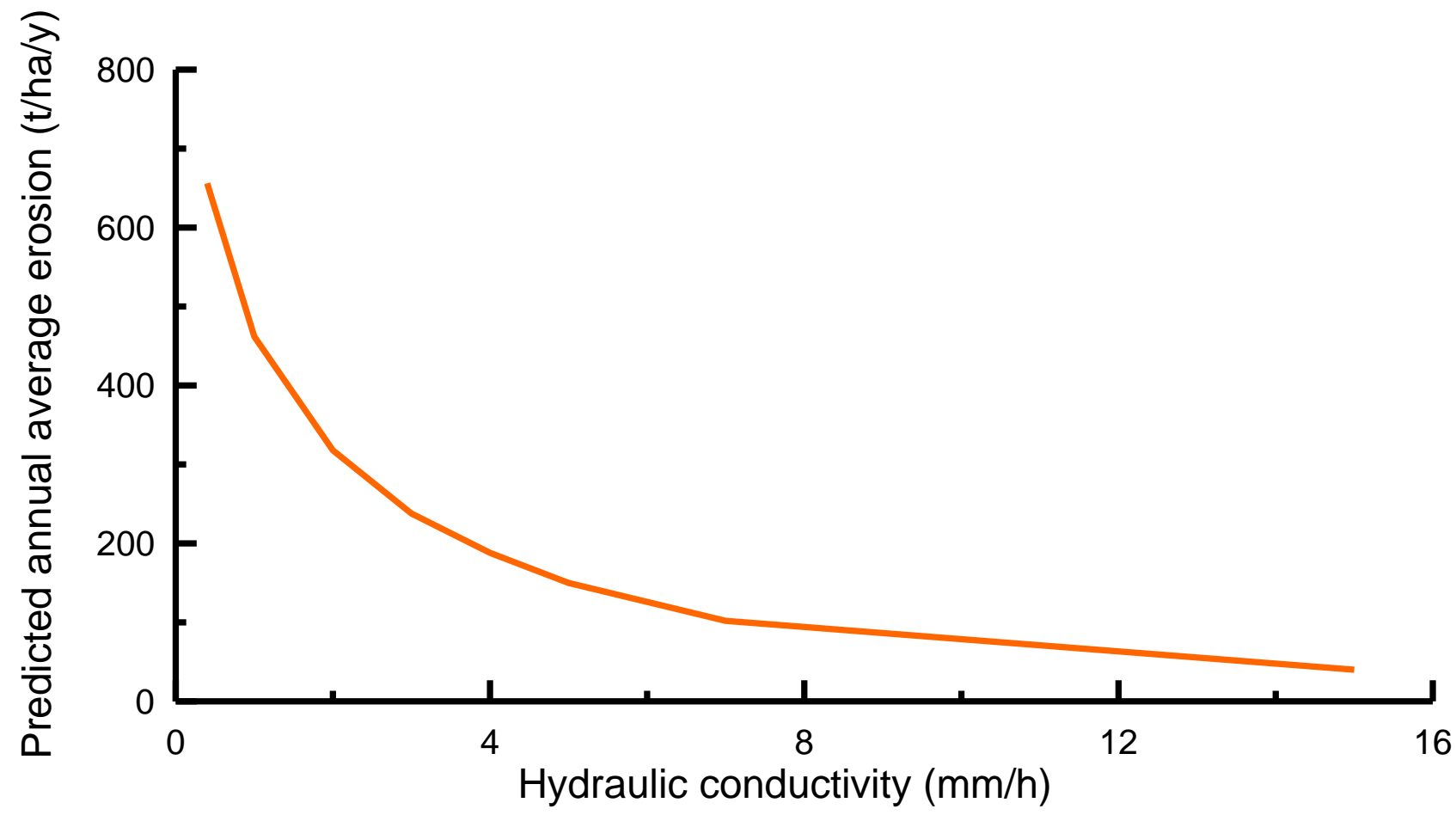

Figure 6 Predicted impact of effective soil hydraulic conductivity on annual erosion from $60 \mathrm{~m}$ high slope of bare soil on $16 \%$ gradient, Hunter Valley climate (from Loch 2010)

For situations where deep drainage is of concern, development of deep-rooted species such as trees is essential to reduce drainage (Yee Yet \& Silburn 2003; Tolmie et al. 2011), and trade-offs between erosion control and drainage control may be necessary as high tree densities have the potential to provide less surface (contact) cover than a grass-dominant vegetation (see e.g. Carroll et al. 2000).

Importantly, for most of these considerations, runoff, erosion and water balance modelling can be used to determine critical levels of surface cover, acceptable levels of initial cumulative erosion, short- and long-term targets for soil infiltration capacity, and necessary levels of tree canopy cover to control deep drainage. Consequently, there is considerable potential for the growing capability to model at least some aspects of ecosystem function to contribute to both rehabilitation practice and to its assessment.

It is noted here that most, if not all, of the preceding discussion considers ecosystem function in terms of making most efficient of use of rainfall and radiation. Soil microbes - in particular mycorrhizae and rhizobia - also merit consideration.

As well, there may well be critical components of an ecosystem separate from those related to water and soil that should be considered in the context of functional groupings, and Laughlin (2014) provides a useful review of these concepts. He identifies both response and effect traits, and notes that:

"Plant traits have been shown to influence primary production, litter decomposition, soil respiration, nutrient cycling and soil moisture retention ..... and their potential for altering ecosystem processes in desirable ways has not yet been fully exploited in ecological restoration projects."

As well, Laughlin (2014) considers application of plant trait concepts to impacts of climate change and to management of invasive species. 


\section{Conclusion}

The desire to have mine site rehabilitation establish specific target ecosystems is understandable and reasonable. However, successful and sustainable establishment of such ecosystems requires a broader definition of the target ecosystem than simply species presence and diversity, with a range of soil attributes being key to ecosystem success. There may also be specific services to be provided by an established ecosystem that are critical to the long-term sustainability of a rehabilitated landform.

As well, in some climatic zones there may be specific ecosystem services required of plants during ecosystem development. These may relate to landscape stability, through prevention or reduction of erosion, or to landscape function, through modification of soil structure and fertility. Many of these services can be identified and - importantly - quantified using runoff/erosion and water balance models. Figure 6 shows an example of how modelling can be used to set targets for soil management (or to demonstrate the importance of soil quality). Figure 4 shows an example of the importance of timing for seeding works, and could be used to set criteria for development of vegetation cover during a wet season to provide stability as erosion potential increases. Once established, models enable a very wide range of conditions and options to be tested. These approaches provide an opportunity to set more effective short- and long-term success criteria for managing mine site rehabilitation.

\section{References}

Carroll, C \& Tucker, A 2000, 'Effects of pasture cover on soil erosion and water quality on central Queensland coal mine rehabilitation', Tropical Grasslands, vol. 34, pp. 254-262.

Carroll, C, Merton, L \& Berger, P 2000, 'Impact of vegetative cover and slope on runoff, erosion, and water quality for field plots on a range of soil and spoil materials on central Queensland coal mines', Australian Journal of Soil Research, vol. 38, pp. 313-327.

Clements, FE 1916, Plant Succession: An Analysis of the Development of Vegetation, Publication 242, Carnegie Institute of Washington, Washington, DC.

Eldridge, DJ, Zaady, E, \& Shachak, M 2002, 'Microphytic crusts, shrub patches and water harvesting in the Negev Desert: the Shikim system', Landscape Ecology, vol. 17, pp. 587-597.

Howard, E, Shemeld, J, \& Loch, R 2010, 'Ramelius Resources' Wattle Dam Project: Achieving bond reduction through leading practice,' Goldfields Environmental Management Group 2010 Workshop.

Isbell, RF 1962, Soils and vegetation of the Brigalow Lands, Eastern Australia, Soils and Land Use Series No. 43. CSIRO:Melbourne.

Kato, H, Onda, Y, Tanaka, Y, \& Asano, M 2009, 'Field measurement of infiltration rate using an oscillating nozzle rainfall simulator in the cold, semiarid grassland of Mongolia', Catena, vol. 76, pp. 173-181.

Koch, JM 1987, 'Nitrogen accumulation in a rehabilitated bauxite mined area in the Darling Range, Western Australia', Australian Forestry Research, vol. 17, pp. 59-72.

Landres, PB, Morgan, P \& Swanson, FJ 1999, 'Overview of the use of natural variability concepts in managing ecological systems', Ecological Applications, vol. 9, pp. 1179-1188.

Laughlin, DC 2014, 'Applying trait-based models to achieve functional targets for theory-driven ecological restoration', Ecology Letters, vol. 17, pp. 771-784.

Littleboy, M, Sachan, RC, Smith, GD, \& Cogle, AL 1996, 'Soil management and production of Alfisols in the semi arid tropics. II. Deriving USDA curve numbers from rainfall simulator data', Australian Journal of Soil Research, vol. 34, pp. $103-111$.

Loch, RJ 2000a, 'Using rainfall simulation to guide planning and management of rehabilitated areas: I. Experimental methods and results from a study at the NorthParkes mine', Land Degradation and Development, vol. 11, pp. 221-240.

Loch, RJ 2000b, 'Effects of vegetation cover on runoff and erosion under simulated rain and overland flow on a rehabilitated site on the Meandu Mine, Tarong', Australian Journal of Soil Research, vol. 38, pp. 299-312.

Loch, RJ 2010, Sustainable landscape design for coal mine rehabilitation, ACARP Project C18024, report published 1/05/2010.

Loch, RJ \& Foley, JL 1994, 'Measurement of aggregate breakdown under rain: comparison with tests of water stability and relationships with field measurements of infiltration', Australian Journal of Soil Research, vol. 32, pp. 701-720.

Loch, RJ \& Lowe, SM 2008, 'A logical framework for design, construction, and rehabilitation of minesite waste rock dumps', A Fourie (ed), Proceedings of the First International Seminar on the Management of Rock Dumps, Stockpiles, and Heap Leach Pads, Australian Centre for Geomechanics, Perth, pp 257-265.

Loch, RJ \& Orange, DN 1997, 'Changes in some properties of topsoil at Tarong Coal - Meandu Mine coalmine with time since rehabilitation', Australian Journal of Soil Research, vol. 35, pp. 777-784.

NSW DECCW (New South Wales Department of Environment, Climate Change and Water) 2010, Brigalow within the Brigalow Belt South, Nandewar and Darling Riverine Plains bioregions, NSW DECCW.

Schwenke, GD, Ayres, L, Mulligan, DR, \& Bell, LC 2000, 'Soil stripping and replacement for the rehabilitation bauxite-mined land at Weipa. II. Soil organic matter dynamics in mine chronosequences', Australian Journal of Soil Research, vol. 38, pp. 371-393.

Squires, H, Priest, M, Sluiter, I, \& Loch R 2012, 'Leading practice waste dump rehabilitation at the Ginkgo mineral sands mine', in AB Fourie and M Tibbett (eds), Mine Closure 2012, Australian Centre for Geomechanics, Perth. 
Tolmie, PE, Silburn, DM, \& Biggs, AJW 2011, 'Deep drainage and soil salt loads in the Queensland Murray-Darling Basin using soil chloride: comparison of land uses', Soil Research, vol. 49, pp. 408-423.

Ward, SC 2000, 'Soil development on rehabilitated bauxite mines in south-west Australia', Australian Journal of Soil Research, vol. 38, pp. 453-64.

Ward, SC \& Pickersgill, GE 1985, 'Nutrient distribution in two eucalypt plantations growing on rehabilitated bauxite mines', Australian Journal of Ecology, vol. 10, pp. 111-124.

Ward, SC, Koch, JM \& Nichols, OG 1990, 'Bauxite mine rehabilitation in the Darling Range, Western Australia', in Proceedings of the Ecological Society of Australia, vol. 16, pp. 557-565.

Westman, WE 1978, 'Inputs and cycling of mineral nutrients in a coastal subtropical eucalypt forest', Journal of Ecology, vol. 66, pp. 513-531.

Whittaker, RH 1953, 'A consideration of climax theory: the climax as a population and pattern', Ecological Monographs, vol. 23, pp. 41-78.

Yee Yet, JS \& Silburn, DM 2003, Deep drainage estimates under a range of land uses in the QMDB using water balance modelling, Department of Natural Resources and Mines, Queensland, QNRM03021. 